\title{
Resting Blood Pressure Values of Adult Athletes
}

\author{
Barbara Varga-Pintér Patrícia Horváth Zsuzsanna Kneffel Zsuzsanna Major \\ Péter Osváth Gábor Pavlik \\ Department of Health Sciences and Sports Medicine, Faculty of Physical Education and Sports Sciences, \\ Semmelweis University, Budapest, Hungary
}

\section{Key Words}

Athletes $\cdot$ Blood pressure $\cdot$ Canoe $\cdot$ Cycling $\cdot$ Kayak ·

Power athletes $\cdot$ Water athletes

\begin{abstract}
Background: Regular physical activity has a favorable effect upon the prevention and treatment of hypertension. Various movements in sports, however, affect blood pressure (BP) differently. Methods: In the present study, the resting BP data of a large number $(3,697)$ of young men and women (age: 19-40 years) who participated in sports medical examinations were compared according to their sport. Athletes were arranged into definite subgroups based on their different sport activities, i.e. if their movement pattern characteristics were similar and no significant intergroup differences were seen in BP values. Results: BP values were lower in the dynamic type athletes (speed, endurance sports and ball games) than in the static type. Out of the endurance athletes, $B P$ values were not lower in cycle racers, kayakers/canoeists and rowers. In water athletes, BP values were higher than in corresponding dry-land athletes. There was a quite large significant difference between the BP values of athletes involved in static muscular activity (power athletes) and dynamic-type strength athletes (combat competitors). Conclusions: Although cycling, kayaking/canoeing and competitive water sports increase BP, as leisure time activities they more than likely do not elevate BP.
\end{abstract}

Copyright $\odot 2011$ S. Karger AG, Basel

\section{Introduction}

One of the beneficial effects of regular physical training could be a decrease in blood pressure (BP), which can play a role in the prevention and treatment of hypertension.

The effect of regular physical exercise on resting $\mathrm{BP}$ reduction is not as acute as the reduction detected in heart rate. According to different large epidemiological and meta-analytic surveys, regular training decreases the $\mathrm{BP}$ of normotensive persons by $3-4 \mathrm{~mm} \mathrm{Hg}$, and also reduces the risk of the development of hypertension disease $[1-5]$. When used in hypertensive patients as monotherapy, it has a BP-decreasing effect of 9-10 $\mathrm{mm} \mathrm{Hg}$ [5-9].

The exact mechanism of the BP-decreasing effect of regular physical exercise is not unambiguously clear. The most probable cause can be modified resting autonomous balance: lower sympathetic and elevated parasympathetic activity $[1,4,10]$, as well as other mechanisms, such as baroreceptor resetting $[11,12]$ or the modified effects of some vasoactive substances (e.g. dopamine [13]) [1, 4, 14, 15]. Both BP-determining factors, namely cardiac output [16-18] and total peripheral resistance [19] can be more or less decreased. Our own investigations, carried out through different methods, showed that cardiac output in normotensive well-trained endurance athletes was lower than in non-trained subjects [20-22].

Researchers agree that regular dynamic activity decreases resting BP more effectively than power training does [23]; however, several authors have reported differ- 
Table 1. Number and age of subjects according to gender and physical activity

\begin{tabular}{|c|c|c|c|c|c|c|}
\hline & \multicolumn{2}{|l|}{ Men } & \multicolumn{2}{|c|}{ Women } & \multicolumn{2}{|l|}{ Total } \\
\hline & $\mathrm{n}$ & mean age $\pm S D$ & $\mathrm{n}$ & mean age $\pm \mathrm{SD}$ & $\mathrm{n}$ & mean age $\pm \mathrm{SD}$ \\
\hline Athletes & 2,169 & $24.4 \pm 4.9$ & 1,337 & $22.5 \pm 3.7$ & 3,506 & $23.7 \pm 4.6$ \\
\hline Controls & 93 & $27.9 \pm 6.5$ & 98 & $25.9 \pm 5.9$ & 191 & $26.8 \pm 6.3$ \\
\hline Total & 2,262 & $24.5 \pm 5.0$ & 1,435 & $22.8 \pm 4.0$ & 3,697 & $23.8 \pm 4.7$ \\
\hline
\end{tabular}

ences in the depth of the changes, depending on the sport activity.

According to Blomqvist and Saltin [24], sport activity carried out only with the upper body leads to higher BP, but Kameyama et al. [25] did not find higher than usual BP values in canoeists. Cubero et al. [26] found higher BP values $(128 / 71 \mathrm{~mm} \mathrm{Hg})$ in young (15-18 years) canoeists than in cyclists $(122 / 67 \mathrm{~mm} \mathrm{Hg})$ and soccer players $(117 / 65 \mathrm{~mm}$ $\mathrm{Hg}$ ). Jovanović and Jovanović [27] discovered lower BP values in elite water polo players $(129 / 83 \mathrm{~mm} \mathrm{Hg})$ and handball players $(131 / 82 \mathrm{~mm} \mathrm{Hg})$ than in non-athletes $(139 / 86$ $\mathrm{mm} \mathrm{Hg}$ ) - though the BP values of all 3 groups proved to be higher than the age-relevant means. Wray et al. [28] found relatively low values in 21- to 25-year-old cyclists. There are data regarding the $\mathrm{BP}$ values of swimmers and water athletes, showing them to be slightly [29] or significantly [30] higher than dry-land athletes. The higher BP values of power athletes can be read about, for example, in the work of Jost et al. [31] and Longhurst and Stebbins [32].

To the best of our knowledge, until now there have been very few studies with a large sample base $[33,30]$ dealing with the resting $\mathrm{BP}$ of athletes who participate in different kinds of sports; the numbers of subjects in these studies were several hundred athletes. In the present study, an attempt was made to examine the resting BP values of an even larger number of athletes engaged in a wide variety of different sports events. To this end, the resting $\mathrm{BP}$ values of young adult athletes and non-athletic university students who had come to the medical consulting room of the Department of Health Sciences and Sports Medicine of the Faculty of Physical Education and Sports Sciences of the Semmelweis University (The Hungarian University of Physical Education, before 2000) between 1987 and 2008 were compared according to their kinds of sports. Subjects came mostly to obtain medical permission for competitive sports or to participate in some scientific investigations. In the comparison, the different sports activities of the athletes were taken into account, first separately, and then the athletes were grouped into definite subgroups according to similarity of movement pattern characteristics and BP intergroup uniformity. A shorter presentation of these results has been published earlier [34]; this time we provide a more detailed presentation with further comparisons and explanations.

\section{Methods}

In the present study, adult competitors were evaluated. The subjects were 19-40 years old (table 1). All subjects were free of any internal diseases and medication, and some of them only used vitamin products. Almost all of the subjects were Hungarian citizens; only very few subjects were foreigners studying at our university or guest players playing in teams in the Hungarian championship. Foreign subjects were all Europeans of Caucasian descent. No distinction was made according to the performance level of the athletes: national competitors, first-class and lower-level athletes were all involved in the sports groups; $54.6 \%$ of our athletes were top level (national or first-class level) and $46.4 \%$ were lower-level athletes. All of the athletes participated regularly in competitions or championships. Top-level and lower-level athletes trained for 11.2 and $8.6 \mathrm{~h}$ per week, respectively. The BPs of the athletes of the total 53 sporting disciplines were analyzed in the study.

To simplify orientation within the numerous sports activities, we formed subgroups on the basis of movement patterns and the prevalence of athletes' sports abilities (power, speed, endurance) in the different sports events. The BP values of the athletes of the different sport types within the subgroups were assessed using ANOVA, and a group was formed only if no significant differences were seen. At the end of the analysis, the subgroups presented in table 2 were formed.

Dry-land endurance sports (Dry-l. end.) are sports events in which athletes train themselves through long-lasting continuous exercise and compete in disciplines lasting more than 4-5 min up to several hours in the land. First, field and road cycle racers and kayak/canoe competitors - as their bodies are in contact only with the air, similarly to other dry-land athletes - were also classified in this subgroup, but the BP values of the male participants were higher, and therefore these 2 groups were evaluated separately. It should be noted that the BP values of the mountain bike group, however, did not differ from the BP values of the whole group of dry-land endurance athletes.

The group of water endurance sports (W. end.) is not absolutely typical, and contains competitors engaged in swimming, 
triathlon and pentathlon. The reasons for putting these sports in this subgroup are as follows:

- Swimming competitions contain a wide range of disciplines: relatively few typical sprint events, mostly middle-distance competitions and long-distance swimming. No open water swimmers were in our sample. Most swimmers, however, participate in a very wide range of disciplines and all of the swimmers performed endurance training sessions, which is why they were classified into the water endurance group.

- Another characteristic feature of swimming is that the competitive age is rather young - there are only a few swimmers over 18 years, and they are usually the most successful competitors. In our sample, there were only 8 male and 4 female swimmers (16.4 and $17.4 \%$ of the water endurance group, respectively).

- Pentathlon and triathlon are not typical swimming activities; they are mixed sports events which contain many endurance elements. Most of these athletes, however, began their athletic career with swimming, and it also constitutes a substantial part of their training activity, and therefore they were classified in this group. This means that the water endurance group contains athletes who take part in a substantial amount of water-based activities.

Cyclists were classified into a separate group (Bicyc.), as their $\mathrm{BP}$ proved to be higher than that of the athletes of other dry-land endurance sports. All of the competitors were road cycle racers, and some of them also took part in field competitions.

Kayak/canoe and rowing competitors (Kc-row) were also put in an independent group. One reason for this was that the duration of their competitions belongs to the middle-distance range, which requires submaximal intensity, as opposed to long-distance races. The other reason was that the $\mathrm{BP}$ of the male competitors was higher than that of the other dry-land endurance athletes ( $\mathrm{t}$ test for independent samples, $\mathrm{p}<0.01$ ). As oarsmen, rowers were also classified into this group, although their share of the whole group was rather small (7.1\%).

Dry-land ball games (Dry-l. ball) contain all ball games, independent of whether they are played in teams, pairs or individually. An overwhelming part of this group (83.8\%) is formed by team ball game players: basketball, soccer, handball and volleyball; in soccer almost all of the players were males.

The group of water ball games (W. polo) contains water polo players. Due to Hungary's success in this sport, there is a considerably large amount of both male and female water polo players in this study.

The Power group includes athletes whose sports activities contain mostly static power elements: namely weight lifting, body building and the throwing disciplines.

Combat sports (Combat) represent the sports activities in which dynamic strength is dominant. Approximately half of the group includes judo and karate competitors, $17 \%$ were athletes from the 'classic' combat sports (wrestling and boxing), while the others were competitors in different combat and martial sports.

The group of sprinters and jumpers (Sprjump) includes athletes whose sports activity is characterized by explosive strength. Most athletes from this group were track and field athletes: jumpers and sprint runners (up to 400-meter events). In addition, fencing and short track speed skating were classified into this group, as these sports activities also feature explosive strength as the predominant ability.
Table 2. Formation of subgroups of athletes

\begin{tabular}{|c|c|}
\hline Sports subgroups & Sports within the groups \\
\hline $\begin{array}{l}\text { Dry-land endurance sports } \\
\text { (Dry-l. end.) }\end{array}$ & $\begin{array}{l}\text { middle- and long-distance running, } \\
\text { mountain biking, race walking, } \\
\text { cross-country skiing, orienteering }\end{array}$ \\
\hline $\begin{array}{l}\text { Water endurance sports } \\
\text { (W. end.) }\end{array}$ & swimming, triathlon, pentathlon \\
\hline Bicycling (Bicyc.) & cycling \\
\hline $\begin{array}{l}\text { Kayaking/canoeing and } \\
\text { rowing (Kc-row) }\end{array}$ & kayaking/canoeing and rowing \\
\hline $\begin{array}{l}\text { Dry-land ball games } \\
\text { (Dry-l. ball) }\end{array}$ & $\begin{array}{l}\text { soccer, basketball, handball, tennis, } \\
\text { korfball, volleyball, ice hockey, } \\
\text { hockey, floorball, badminton }\end{array}$ \\
\hline Water ball games (W. polo) & water polo \\
\hline $\begin{array}{l}\text { Static power sports } \\
\text { (Power) }\end{array}$ & $\begin{array}{l}\text { weight lifting, body building, } \\
\text { athletic throwing disciplines }\end{array}$ \\
\hline $\begin{array}{l}\text { Combat sports } \\
\text { (Combat) }\end{array}$ & $\begin{array}{l}\text { wrestling, judo, boxing, karate, } \\
\text { kickboxing, kung-fu, taekwondo, } \\
\text { taiji, muay thai, kempo, kendo }\end{array}$ \\
\hline $\begin{array}{l}\text { Sprint and jumping events } \\
\text { (Sprjump) }\end{array}$ & $\begin{array}{l}\text { sprinting, jumping disciplines, } \\
\text { fencing, speed skating }\end{array}$ \\
\hline $\begin{array}{l}\text { Dry-land artistic sports } \\
\text { (Art./dry-l. art.) }\end{array}$ & $\begin{array}{l}\text { gymnastics, aerobics, dance, diving, } \\
\text { rhythmic gymnastics, synchronized } \\
\text { skating }\end{array}$ \\
\hline $\begin{array}{l}\text { Water artistic sports } \\
\text { (Synch. sw.) }\end{array}$ & synchronized swimming \\
\hline
\end{tabular}

Moderate-intensity sports sailing, shooting, car racing, riding (Mod.)

Controls (non-athletes)

The group of dry-land artistic sports (Art/Dry-l. art.) mostly contains competitors from artistic gymnastics, aerobic and rhythmic gymnastics. Due to the inclusion of the latter 2 sports events, the share of female athletes is higher in this group. The relatively few divers were also included in this group, as their sports activity is mostly similar to that of artistic gymnastics, and they perform in the air and only the arrival happens in the water.

The group of water artistic sports (Synch. sw.) contains only one branch of sports, which is synchronized swimming. It is quite obvious that this group contains only a small number of competitors, who are all female.

Moderate-intensity sports (Mod.) are those sports in which muscular activity does not determine performance. In our sample, these athletes were mostly sailors (83.7\%), and the remaining athletes were car racers, riders and shooters.

Non-athletic subjects served as controls; these were healthy persons within the same age range, engaging in no regular physi- 
Table 3. Summary of subjects' data

\begin{tabular}{|c|c|c|c|c|c|c|}
\hline & \multicolumn{3}{|l|}{ Men } & \multicolumn{3}{|c|}{ Women } \\
\hline & $\mathrm{n}$ & age, years & weekly training, h & $\mathrm{n}$ & age, years & weekly training, h \\
\hline Dry-l. end. & 117 & $24.9 \pm 5.0$ & $14.1 \pm 6.0$ & 47 & $22.7 \pm 4.6$ & $13.0 \pm 6.6$ \\
\hline W. end. & 49 & $24.1 \pm 4.3$ & $24.6 \pm 10.7$ & 22 & $22.1 \pm 4.0$ & $26.3 \pm 11.1$ \\
\hline Bicyc. & 30 & $23.7 \pm 3.7$ & $23.8 \pm 6.6$ & - & - & - \\
\hline Kc-row & 47 & $24.3 \pm 4.1$ & $24.1 \pm 7.2$ & 9 & $24.0 \pm 3.8$ & $26.5 \pm 6.8$ \\
\hline Dry-1. ball & 849 & $24.0 \pm 4.9$ & $11.8 \pm 5.4$ & 514 & $22.3 \pm 3.6$ & $11.2 \pm 6.2$ \\
\hline W. polo & 583 & $25.4 \pm 5.4$ & $14.7 \pm 7.0$ & 299 & $23.6 \pm 4.3$ & $11.5 \pm 6.0$ \\
\hline Power & 74 & $22.4 \pm 3.1$ & $17.1 \pm 5.9$ & 45 & $22.1 \pm 2.8$ & $12.4 \pm 6.2$ \\
\hline Combat & 139 & $24.8 \pm 4.7$ & $11.9 \pm 6.6$ & 48 & $23.0 \pm 3.6$ & $10.4 \pm 5.8$ \\
\hline Sprjump & 155 & $22.7 \pm 2.9$ & $13.6 \pm 4.6$ & 105 & $21.1 \pm 2.1$ & $15.3 \pm 4.2$ \\
\hline Art./dry-l. art. & 96 & $22.9 \pm 2.8$ & $12.2 \pm 4.6$ & 223 & $22.3 \pm 3.3$ & $9.0 \pm 5.1$ \\
\hline Synch. sw. & - & - & - & 11 & $22.5 \pm 3.1$ & $15.3 \pm 4.2$ \\
\hline Mod. & 30 & $30.4 \pm 6.2$ & $10.0 \pm 0$ & 14 & $23.5 \pm 4.2$ & $15.0 \pm 6.2$ \\
\hline Controls & 93 & $27.9 \pm 6.5$ & 0 & 98 & $25.9 \pm 5.9$ & 0 \\
\hline Total & 2,262 & $24.5 \pm 5.0$ & $13.2 \pm 7.9$ & 1,435 & $22.8 \pm 4.0$ & $10.4 \pm 7.4$ \\
\hline
\end{tabular}

Data presented as means $\pm \mathrm{SD}$.

cal activity or leisure time sports. Most of them were university students or subjects employed in sedentary jobs.

Table 3 contains the mean ages and weekly training times of our groups.

Measurements were made using an Omszöv Medic OM-362 mercury tensiometer. Subjects were asked about their physical activity performed on the day of examination, and only those who had undertaken no exercise on that day were included in the study. They sat at rest for $15 \mathrm{~min}$ before the carrying out of the measurements, and remained in a sitting position throughout the measuring. The first sound upon the release of the cuff's pressure indicated systolic $\mathrm{BP}(\mathrm{SBP})$; the diastolic value (DBP) was the value read when the throbbing sound changed to whooshing sound. If the sounds were not clearly defined, the measurement was repeated. Measurements were performed mostly by sports medical doctors. Only some technicians participated in the measurement, who were educated and supervised by medical doctors.

Statistical calculations were performed with Statistica 8.0 for Windows (StatSoft). First, we performed one-way ANOVA, and later post hoc Tukey tests for unequal numbers to reveal the differences among the groups. In the figures, means \pm SEM are indicated. In some cases, $t$ tests for independent samples were used to reveal differences between identical dry-land and water sports subgroups.

\section{Results}

The popularity and accessibility of sports activities is very different, and it is quite obvious that the numbers of subjects varied greatly in the investigated groups. Ball games seem to be the most popular; the number of sub- jects in these groups is by far the largest, while groups containing only selected sports activities contained the smallest numbers of participants.

SBP and DBP values for men (fig. la, b) and women (fig. 1c, d) are presented in descending order. For the results of the post hoc Tukey test, the significant differences between the groups are illustrated by the lines on the right side of the graphs.

The male cyclists' and static power athletes' SBPs were the highest, and these values significantly differed from the values of most of the other groups. Following them, in order, were the kayaker-canoeist-oarsmen group, nonathletes and water polo players. The water endurance athletes' group had lower SBP than power athletes and cycle racers, but their results did not differ significantly from the following groups. The artistic athletes and the moderate-intensity sports athletes had the lowest values.

DBP results were similar to the results of SBP, except for the fact that water polo players had higher DBP while kayak-canoe-rower competitors had a slightly lower rank. The DBP values of the groups were closer to each other than the SBP, and only cyclists, power athletes and water polo players had significantly higher DBP values than the groups with the lowest BP values.

In women, both SBP and DBP levels were significantly lower than in men (both $\mathrm{p}<0.0001$ ); the difference was greater in the SBP values. Men's mean SBP value was $125.6 \pm 13.0 \mathrm{~mm} \mathrm{Hg}$ (range 137.1-117.6); women's mean 


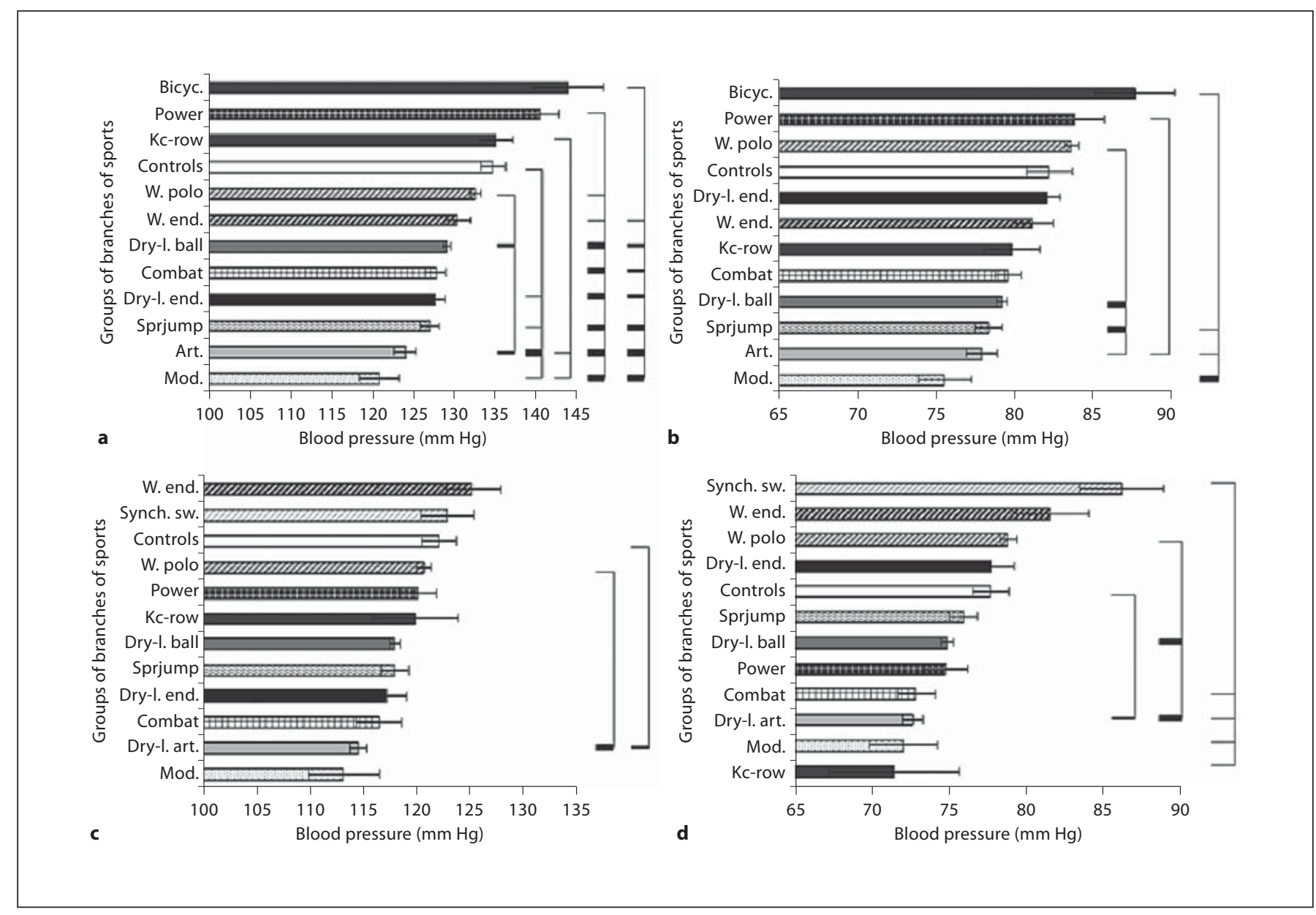

Fig. 1. Men's SBP values (a), men's DBP values (b), women's SBP values (c) and women's DBP values (d) in different sports subgroups (means \pm SEM). Lines for significance: thin: $p<0.05$; medium: $p<0.01$; thick: $p<$ 0.001. Differences are presented compared to the group at the upper point of each vertical line.

SBP was $116.1 \pm 13.4 \mathrm{~mm} \mathrm{Hg}$ (range 119.9-111.5). DBPs in males were $79.5 \pm 9.7 \mathrm{~mm} \mathrm{Hg}$ (range 85.4-74.5), and in females $75.3 \pm 12.7 \mathrm{~mm} \mathrm{Hg}$ (range 84.2-70.9).

In women, differences among the various groups were smaller than in men; there were far less significant differences. It should be noted, however, that in women significant differences were found more frequently in the DBP than in the SBP values. The rank of the sports groups is basically similar to that of men. It is apparent that water athletes (synchronized swimmers, water endurance athletes and water polo players) had the highest BP values. Female kayak-canoe competitors and power athletes had lower positions in the rank of subgroups than their male counterparts.

In regards to SBP, only non-athletes and water polo players showed significantly higher BP than dry-land ar- tistic athletes. Water polo players had higher DBP than dry-land ball-game players and dry-land artistic athletes. The highest DBP was found in synchronized swimmers; it was significantly higher than the values of the combat, dry-land artistic, moderate-intensity athletes and kayakcanoe-rowing competitors (fig. 1c, d).

\section{Discussion}

In the present study, the BP values of athletes were compared according to the kinds of sports they participated in.

The resting $\mathrm{BP}$ values in men were significantly higher than in women; the difference was greater in the systolic than in the diastolic values. These results are in ac- 
cordance with the common experience that the prevalence of hypertension in young white men is considerably higher than in women [35]. The differences between groups of women were also smaller than in men, but the differences between the subgroups were similar in the two genders. Results are in accordance with data from other authors [5], according to which BP in athletes is only 3-4 mm Hg lower than in normotensive non-athletes.

As regards the resting $\mathrm{BP}$ values of our different groups, the main findings can be summarized as follows:

- BP values of dynamic-type athletes (speed, endurance and artistic sports, ball games) were lower than those of static-type athletes.

- Within the group of dry-land endurance athletes, cyclers and kayakers-canoeists-rowers had higher BP than the other endurance athletes.

- Water athletes' BP was higher than that of their dryland counterparts.

- The difference between the BP values of static and dynamic power athletes is very marked. Static-type power athletes rank highly among the different groups, while dynamic strength athletes rank towards the lower end.

BP Values of Dynamic-Type Athletes Were Lower than Those of Static-Type Athletes

This first statement does not sound very new, as it is well known that dynamic sports are more suitable for decreasing BP than static sports $[6,14,23,35,36]$. Intensive movement augments the speed of blood circulation and cardiac output increases, but as muscular arterioles dilate, total peripheral resistance decreases. As a consequence, only SBP increases, while the DBP does not change or it decreases. During static load, due to the contraction of muscular vessels and to the holding of breath, i.e. to an increased thoracic pressing, the peripheral resistance rises, and consequently, primarily DBP increases. Naturally, it can be dangerous for hypertensive persons, and generally it is not recommended in the prevention of hypertension. There are, however, some observations according to which moderate-intensity resistance training can also aid in reducing resting $\mathrm{BP}$ [37].

\section{Of the Dry-Land Endurance Athletes, Cyclers and} Kayaker-Canoeists Had Higher BP

It was conspicuous that in the male dry-land endurance athletes' group, cyclists had the highest BP, and kayak-canoe competitors also showed a slightly higher $\mathrm{BP}$ level than the other athletes. In our sample there were no female cyclers, and the relatively few kayak-canoe competitors showed only moderately higher BP values.

In accordance with other authors [24], it can be postulated that if the physical activity of the different parts of the body is unequal, namely, only one part performs dynamic activity and the other one does not, then total peripheral resistance, and, consequently, DBP does not decrease. It can be supposed that the static position of the upper limbs during cycling and the limited movement of the lower limbs during kayaking/canoeing and rowing impedes a definite decrease in total peripheral resistance, and the daily repetition of this kind of exercise induces a relatively high BP value in these athletes. BP is even higher in cycle racers, because their upper limb is really in a static position during training sessions or competitions, while in the paddling sports the lower limb is not absolutely passive. Another factor contributing to the elevated $\mathrm{BP}$ values of cyclers is the very frequent uphill sections they race on during competitions, which elicit an increased pressing load.

Of course, these findings concern bicycle and kayakcanoe-rower competitors. In those who do these sports as leisure time physical activities or as a means of transport (bicycle, paddling), these unfavorable effects are unlikely or only manifest to a small extent.

\section{Water Athletes' BP Was Higher than That of Their \\ Dry-Land Counterparts}

Another apparent but rather unusual result is the relatively high BP values of water athletes. In almost all comparisons, the BP values of water athletes proved to be higher than that of the corresponding dry-land groups. According to the ANOVA and the post hoc Tukey test, SBP values were significantly higher in the male water polo players than in the dry-land ball game players, and DBP values were higher for the male and female water polo players than for the dry-land ball game players. DBP values were also higher for synchronized swimmers than for the female dry-land artistic athletes.

In comparing the $\mathrm{BP}$ of the corresponding water and dry-land groups with the t test for independent samples, further significant differences were found: all female water athletes had higher SBP than the female dry-land athletes. In the endurance groups, the difference was 121.9 \pm 10.9 versus $115.0 \pm 10.9 \mathrm{~mm} \mathrm{Hg}(\mathrm{p}<0.02)$, in the ballgame groups the values were $117.9 \pm 10.6$ versus $115.5 \pm$ $10.5 \mathrm{~mm} \mathrm{Hg}(\mathrm{p}<0.01)$, and in the artistic groups the BP values were $119.9 \pm 7.2$ versus $112.7 \pm 10.1 \mathrm{~mm} \mathrm{Hg}(\mathrm{p}<$ $0.05)$. It was only in the group of male endurance athletes in which no difference was seen between water and dry- 
Table 4. SBP and DBP values ( $\mathrm{mm} \mathrm{Hg}$ ) of dry-land and aquatic athletes

\begin{tabular}{|c|c|c|c|c|c|c|c|c|}
\hline & & \multicolumn{3}{|c|}{ Dry-land athletes } & \multicolumn{3}{|c|}{ Aquatic athletes } & \multirow{2}{*}{$\begin{array}{l}\mathrm{p} \text { values } \\
\text { (dry land vs. aquatic) }\end{array}$} \\
\hline & & $\mathrm{n}$ & mean & $\mathrm{SD}$ & $\mathrm{n}$ & mean & SD & \\
\hline Male & $\begin{array}{l}\text { SBP } \\
\text { DBP }\end{array}$ & 1,537 & $\begin{array}{r}124.7 \\
78.2\end{array}$ & $\begin{array}{r}12.7 \\
9.4\end{array}$ & 632 & $\begin{array}{r}127.3 \\
81.6\end{array}$ & $\begin{array}{r}13.4 \\
9.5\end{array}$ & $\begin{array}{l}<0.001 \\
<0.001\end{array}$ \\
\hline Female & $\begin{array}{l}\text { SBP } \\
\text { DBP }\end{array}$ & 1,004 & $\begin{array}{r}114.9 \\
73.6\end{array}$ & $\begin{array}{r}10.7 \\
8.4\end{array}$ & 332 & $\begin{array}{r}118.3 \\
78.0\end{array}$ & $\begin{array}{r}10.5 \\
8.4\end{array}$ & $\begin{array}{l}<0.001 \\
<0.001\end{array}$ \\
\hline
\end{tabular}

land athletes. The differences between dry-land and aquatic athletes are seen even more clearly if we compare the $\mathrm{BP}$ values of the summarized groups of male and female athletes from the two types of sports; in each comparison highly significant differences can be seen (table 4).

The higher BP values of the aquatic athletes seem to be especially important, as numerous past swimmers or water polo players are being treated for hypertension in their adult years.

The higher BP values of water athletes are not unknown in the history of examining athletes' BP values. In some investigations a few decades ago, the water athletes' $\mathrm{BP}$ values were already found to be higher than that of dry-land athletes, so a definite question suggesting the existence of a 'swimmer hypertension' arose [29, 30, 33]. In one of our earlier works, we also mentioned that the $\mathrm{BP}$ values of water athletes seemed to be higher [4].

Aquatic exercise could elicit higher BP values in several ways $[29,30,33,38]$.

- The arm-orientated work of water athletes, with an equivalent oxygen consumption, can lead to higher sympathetic activity, and hence to higher BP values than work involving the lower extremities.

- The hydrostatic pressure of water compresses the skin and muscular blood vessels, not allowing them a meaningful widening; this leads to a lower peripheral vasodilatation during physical load than in dry-land athletes.

- Movement in the water is performed against a greater resistance, similar to that in uphill running or biking.

- The cold temperature of the water can also diminish peripheral vasodilatation. In competitive sports, the water temperature is usually approximately $24-26^{\circ} \mathrm{C}$ and sometimes (especially in open water competitions) even colder. We must take into consideration, however, that the body temperature, especially the core temperature, is $10-15^{\circ} \mathrm{C}$ higher. It is possible that the water is subjectively quite pleasant to the athlete, but this more or less cooler temperature impedes an intensive peripheral vasodilatation.

- In the dry-land activities the body temperature increases, and the defence against this is extensive perspiration with a significant loss of salt. In the water, body temperature is stabilized, and sweating is far less; sodium retention occurs, and sodium-chloride concentration remains much higher than in dry-land activities.

- Due to heat-regulation problems, the body weight and body fat percentage of water athletes are usually a little higher than those of dry-land athletes. The difference is the most significant in water polo players, where increased physical strength and a bulky body constitution have a lot of advantages.

- The extremely hard physical nature of water polo and the long-lasting underwater activity of synchronized swimmers contribute to intensive BP elevation.

From these peculiarities and from the fact that our water-endurance athletes were not pure water athletes, we can understand that differences were more marked in the ball game players and the artistic sports competitors. As factors moderating the BP-decreasing effect of aquatic physical activity mostly influence peripheral vasoconstriction, total peripheral resistance is supposed to be higher in water athletes [29]; it can be understood that differences in diastolic values are slightly greater than in the systolic values.

On the other hand, the general experience regarding the benefits of swimming is very favorable. It has numerous advantageous effects, for example, a mild load on the musculoskeletal system and a pleasant environment. Because of these effects, swimming is usually recommended as a leisure time or recreational physical activity. Some authors have published work on swimming's BPreducing effect in older, hypertensive and obese patients [39]. 
Taken together we would not recommend people giving up aquatic sports as a voluntary recreational activity, but our own results as well as the aforementioned other results warn us that some caution is required. It can be supposed for example that if somebody is not experienced in swimming and takes exercise in a crowded cold-water pool, his/her BP will not decrease during physical activity.

We recommend controlling the subjects' BP after water sports activity, and adapting the training program based on the results, considering even decreasing or omitting swimming activity from their training program if undesirable BP values are detected. On the other hand, these results encourage us to perform further investigations in reference to some of the important details, like the participation of BP-determining factors, hereditary background, age and body weight relationship, etc.

\section{Difference between BP Values of Static and Dynamic}

Power Athletes Is Very Marked

It is not surprising that there is a difference between the BP values of static and dynamic power athletes, but the extent of the difference was unexpected: static type power athletes (weightlifters, body builders, throwers) ranked highly in the different groups, while dynamic strength athletes like combat athletes (judo, karate, boxing, wrestling and different kinds of martial arts) ranked toward the lower end.

Weightlifters' higher resting BP has already been reported based on data from Olympic Games' participants in 1928 [40], and later it was supported by several other publications [33, 41]. During static exercises, the contraction of large masses of muscles, the breath holding and the high pressing load results in an increase in total peripheral resistance, and in the extensive elevation in the DBP, and consequently, in the SBP.

It is quite certain that dynamic power activities (combat sports) require significant muscular power as well. It seems, however, that the high proportion of movement elements can effectively compensate for the BP-elevating effect of static exercise, and is enough to bring about a lower than average BP.

In our sample differences between the two types of power athletes were more apparent in males; in females, $\mathrm{BP}$ values were only moderately higher in the static group than in the dynamic one, and there was no difference in DBP. It is possible that female static athletes do not perform such highly intensive power elements in their training program as male athletes do, and maybe the fewer training hours can also have an impact on the results, but it is not excluded that the protective effect of female sexual hormones plays an important role in this difference. Genders had similar distribution in competitive levels in our sample, the only different was that in the top-level there were more males than females.

Our results clearly indicate that in studies dealing with the effects of different types of sports, static and dynamic power athletes cannot be discussed in one common group as 'power athletes' as a basic cardiovascular characteristic, namely BP, is quite different between the two groups.

\section{Conclusion}

The resting BP values of a large number of athletes were compared according to the types of sports they participated in. The BP values of most of the athletes were lower than those of non-athletes; however, there were some groups of athletes who had elevated BP values. These were the water athletes, static power athletes and athletes whose sports activity is restricted to only one (upper or lower) part of the body.

\section{Acknowledgments}

The study was carried out with the support of the Hungarian Society of Hypertension. The authors extend their deep thanks to Mr. Mike Leszkai for his help with the language.

References per KH: Physical fitness and incidence of hypertension in healthy normotensive men and women. JAMA 1984;252:487-490.

$\checkmark 2$ Bove AA, Sherman C: Active control of hypertension. Physic Sportsmed 1998;26:4553.

- 3 Paffenbarger RS Jr, Wing AL, Hyde RT, Jung DL: Physical activity and incidence of hypertension in college alumni. Amer J Epidemiol 1983;117:245-257.

4 Pavlik G, Bánhegyi A, Olexó Zs, Sidó Z, Frenkl R: Role of regular physical training in the prevention and treatment of hypertension (article in Hungarian). Hypert Nephrol 2002;6:77-85.

5 Wallace JP: Exercise in hypertension. Sports Med 2003;33:585-598.

6 Apor P: Treatment of patients with hypertension with the help of physical activity (article in Hungarian). Hypert Nephrol 1997;1: 172-176. 
7 Chintanadilok J, Lowenthal D: Exercise in treating hypertension. Phys Sportsmed 2002;30:11-23, 50.

8 Hagberg JM, Park JJ, Brown MD: The role of exercise training in the treatment of hypertension. Sports Med 2000;30:193-206.

-9 Higashi Y, Yoshizumi M: Exercise and endothelial function: role of the endothelium-derived nitric oxide and oxidative stress in healthy subjects and hypertensive patients. Pharmacol Ther 2004;102:87-96.

10 Buckworth J, Convertino VA, Cureton KJ, Dishman RK: Increased finger arterial blood pressure after exercise detraining in women with parental hypertension: autonomic tasks. Acta Physiol Scand 1997;160:29-41.

- 11 Monahan KD, Dinenno FA, Tanaka H, Clevenger CM, DeSouza CA, Seals DR: Regular aerobic exercise modulates age-associated declines in cardiovagal baroreflex sensitivity in healthy men. J Physiol 2000;529:263-271.

12 Lénárd ZM, Studinger P, Mersich B, Pavlik G, Kollai M: Cardiovagal autonomic function in sedentary and trained offspring of hypertensive parents. J Physiol 2005;563: 1031-1038.

13 Gilbert C: Optimal physical performance in athletes: key roles of dopamine in a specific neurotransmitter/hormonal mechanism. Mech Ageing Dev 1995;84:83-102.

14 Jákó P: The Basics of Sports Medicine (in Hungarian). Budapest, Országos Sportegészségügyi Intézet, 2003, pp 81-82.

15 Pavlik G: Regular physical exercise: its role in preventing and treating hypertension (in Hungarian). Komplementer Medicina 1999; 3:6-9.

16 Dickhuth HH: Sport physiology, Sports medicine (in Hungarian). Budapest, Dialóg Kampus, 2005, p 28.

17 Jennings G, Nelson L, Dewar E: Antihypertensive and haemodynamic effects of one year's regular exercise. J Hypertens 1986; 4(suppl 6):S659-S661.
18 Reiling MJ, Bare LA, Chase PB, Seals DR: Influence of regular exercise on 24-hour blood pressure (BP24) in middle aged and older persons with mild essential hypertension (EH). Med Sci Sports Exerc 1990;22:S48.

-19 DePlaen JE, Detry JM: Hemodynamic effects of physical training in established arterial hypertension. Acta Cardiol 1980;35:179188.

20 Pavlik G, Molnár G, Farsang C, Frenkl R: Cardiac output and total peripheral resistance in athletes and in non-athletes at rest. Acta Physiol Hung 1980;55:13-18.

21 Pavlik, G, Bachl N, Wollein W, Lángfy G, Prokop L: Resting echocardiographic parameters after cessation of regular endurance training. Int J Sports Med 1986;7:226231.

22 Pavlik G, Major Z, Varga-Pintér B, Jeserich M, Kneffel Z: The athlete's heart: part I (review). Acta Physiol Hung 2010;97:337-353.

23 Whelton SP, Chin A, Xin X, He J: Effect of aerobic exercise on blood pressure: a metaanalysis of randomized, controlled trials. Ann Intern Med 2002;136:493-503.

24 Blomqvist CG, Saltin B: Cardiovascular adaptations to physical training. Ann Rev Physiol 1983;45:169-189.

25 Kameyama, O, Shibano K, Kawakita H, Ogawa R, Kumamoto M: Medical check of competitive canoeists. J Orthop Sci 1999;4:243249.

-26 Cubero GI, Batalla A, Reguero JJR, Barriales $\mathrm{R}$, Gonzales V, De la Iglesia JL, Terrados N: Left ventricular mass index and sports: the influence of different sports activities and arterial blood pressure. Int J Cardiol 2000; 75:261-265.

27 Jovanović J, Jovanović M: Blood pressure, heart rate and lipids in professional handball and water polo players. Med Pregl 2005;LVIII:168-174.

28 Wray DW, Donato AJ, Nishiyama, SK, Richardson RS: Acute sympathetic vasoconstriction at rest and during dynamic exercise in cyclists and sedentary humans. J Appl Physiol 2007;102:704-712.

29 Dickhuth HH, Simon G, Schmid P, Huber G, Keul J: Blutdruckverhalten und kardiale Anpassungserscheinungen bei Hochleistungsschwimmern. Herz Kreislauf 1981;10:485492.
30 Weiss M, Weicker H: Gibt es eine Schwimmer-Hypertonie? Schweiz Ztschr Sportmed 1985;33:122-132.

31 Jost J, Weiss M, Weicker H: Comparison of sympatho-adrenergic regulation at rest and of the adrenoceptor system in swimmers, long-distance runners, weight lifters, wrestlers and untrained men. Eur J Appl Physiol Occup Physiol 1989;58:596-604.

32 Longhurst JC, Stebbins CL: The power athlete. Cardiol Clin 1984;15:413-429.

33 Lehmann M, Keul J: Prevalence of hypertension in 810 male sports men. Z Kardiol 1984; 73:137-141.

34 Varga-Pintér B, Horváth P, Kneffel Z, Major Z, Tóth M, Pavlik G: Resting blood pressure in adult athletes (in Hungarian). Sportorvosi Szemle 2009;50:11-16.

35 Farsang Cs: The handbook of hypertension (in Hungarian). Budapest, Medintel, 2000, pp 29-31, 528-529.

36 Van Hoof R, Macor F, Lijnen P, Staessen J, Thijs L, Vanhees L, Fagard R: Effect of strength training on blood pressure measured in various conditions in sedentary men. Int J Sports Med 1996;17:415-422.

- 37 Wiley RL, Dunn CL, Cox RH, Hueppchen NA, Scott MS: Isometric exercise training lowers resting blood pressure. Med Sci Sports Exerc 1992;24:749-754.

38 Holmér I: Physiology of swimming man. Acta Physiol Scand 1974;(suppl 407):1-55.

39 Tanaka H, Bassett DR Jr, Howley ET, Thompson DL, Ashraf M, Rawson FL: Swimming training lowers the resting blood pressure in individuals with hypertension. J Hypert 1997;15:651-657.

40 Bramwell C, Ellis R: Clinical observations on Olympic athletes. Arbeitsphysiologie 1929;2: 51-60.

41 Viitasalo J, Komi P, Karvonen M: Muscle strength and body composition as determinants of blood pressure in young men. Eur J Appl Physiol 1979;42:165-173. 